\title{
Severe syndromic ID and skewed X- inactivation in a girl with NAA10 dysfunction and a novel heterozygous de novo NAA10 p.(His16Pro) variant - a case report
}

Ingrid Bader ${ }^{1 * \dagger}$ (D), Nina McTiernan ${ }^{2 \dagger}$, Christine Darbakk $^{2 \dagger}$, Eugen Boltshauser ${ }^{3}$, Rasmus Ree $^{2}$, Sabine Ebner ${ }^{1}$, Johannes A. Mayr ${ }^{4}$ and Thomas Arnesen $2,5,6$

\begin{abstract}
Background: NAA10 is the catalytic subunit of the major N-terminal acetyltransferase complex NatA which acetylates almost half the human proteome. Over the past decade, many NAA10 missense variants have been reported as causative of genetic disease in humans. Individuals harboring NAA10 variants often display variable degrees of intellectual disability (ID), developmental delay, and cardiac anomalies. Initially, carrier females appeared to be oligo- or asymptomatic with X-inactivation pattern skewed towards the wild type allele. However, recently it has been shown that NAA10 variants can cause syndromic or non-syndromic intellectual disability in females as well. The impact of specific NAA10 variants and the X-inactivation pattern on the individual phenotype in females remains to be elucidated.

Case presentation: Here we present a novel de novo NAA10 (NM_003491.3) C.[47A > C]; [=] (p.[His16Pro];[=]) variant identified in a young female. The 10-year-old girl has severely delayed motor and language development, disturbed behavior with hyperactivity and restlessness, moderate dilatation of the ventricular system and extracerebral CSF spaces. Her blood leukocyte X-inactivation pattern was skewed (95/5) towards the maternally inherited X-chromosome. Our functional study indicates that NAA10 p.(H16P) impairs NatA complex formation and NatA catalytic activity, while monomeric NAA10 catalytic activity appears to be intact. Furthermore, cycloheximide experiments show that the NAA10 H16P variant does not affect the cellular stability of NAA10.

(Continued on next page)
\end{abstract}

\footnotetext{
*Correspondence: i.bader@salk.at

${ }^{\dagger}$ Ingrid Bader, Nina McTiernan and Christine Darbakk contributed equally to

this work.

'Einheit für Klinische Genetik, Universitätsklinik für Kinder- und

Jugendheilkunde, Paracelsus Medizinische Universität, Müllner Hauptstraße 48, A-5020 Salzburg, Austria

Full list of author information is available at the end of the article
}

(C) The Author(s). 2020 Open Access This article is licensed under a Creative Commons Attribution 4.0 International License, which permits use, sharing, adaptation, distribution and reproduction in any medium or format, as long as you give appropriate credit to the original author(s) and the source, provide a link to the Creative Commons licence, and indicate if changes were made. The images or other third party material in this article are included in the article's Creative Commons licence, unless indicated otherwise in a credit line to the material. If material is not included in the article's Creative Commons licence and your intended use is not permitted by statutory regulation or exceeds the permitted use, you will need to obtain permission directly from the copyright holder. To view a copy of this licence, visit http://creativecommons.org/licenses/by/4.0/ The Creative Commons Public Domain Dedication waiver (http://creativecommons.org/publicdomain/zero/1.0/) applies to the data made available in this article, unless otherwise stated in a credit line to the data. 
(Continued from previous page)

Discussion and conclusions: We demonstrate that NAA10 p.(His16Pro) causes a severe form of syndromic ID in a girl most likely through impaired NatA-mediated Nt-acetylation of cellular proteins. X-inactivation analyses showed a skewed X-inactivation pattern in DNA from blood of the patient with the maternally inherited allele being preferentially methylated/inactivated.

Keywords: NAA10, X-linked intellectual disability (XLID), N-alpha-acetyltransferase, Acetylation, NatA, Case report

\section{Background}

A majority of the human proteome is N-terminal acetylated by a group of enzymes named $\mathrm{N}$-terminal $(\mathrm{Nt})$ acetyltransferases (NATs). Eight NATs have been identified so far (NatA-NatH), with NatA-NatF and NatH being expressed in humans [1]. NatA is the major NAT responsible for co-translationally $\mathrm{Nt}$-acetylating nearly half of the human proteome [2]. NatA is composed of the evolutionarily conserved catalytic subunit NAA10 and the auxiliary subunits NAA15, NAA50 and HYPK [3-5]. NAA15 is responsible for anchoring the NatA complex to the ribosome as well as modulating the substrate specificity of NAA10 [6-8]. NatA targets small amino acids like Ser and Thr at the N-termini after the initiator methionine has been removed [2]. Furthermore, there is also a cellular pool of NAA10 that is not bound to NAA15 which is suggested to exert distinct roles in the cell [9]. Firstly, several studies have suggested that NAA10 has lysine acetyltransferase (KAT) activity, catalyzing the acetylation of internal lysines of a number of substrate targets including $\mathrm{Hsp} 70$ and beta-catenin [10-12]. Secondly, NAA10 has been reported to regulate substrates in a non-catalytic manner. For instance, NAA10 has a role in genomic imprinting through direct binding of non-methylated DNA motifs and recruitment of DNMT1 [13, 14]. Finally, monomeric NAA10 also displays NAT activity distinct of its NatA activity in preferring acidic N-termini in vitro [9]. However, no in vivo NAT substrates of monomeric NAA10 have been identified so far. NAA10 is an essential gene and loss of NAA10 is associated with developmental defects and lethality in model organisms [15-18].

The human NAA10 gene is located in $\mathrm{Xq} 28$, and several hereditary or de novo NAA10 variants have been reported to be pathogenic in humans [19]. Originally, a missense variant NAA10 p.(Ser37Pro) was identified in eight males from two families with Ogden syndrome (OMIM\#300855) [20]. The affected boys died between ages 5 and 16 months mainly because of cardiac abnormalities [20]. Their unaffected carrier-mothers showed a skewed Xinactivation pattern [21]. The NAA10 p.(Ser37Pro) variant was found to impair both NatA complex formation and NatA catalytic activity [21]. Since the discovery of Ogden syndrome, various pathogenic NAA10 variants have been reported in both males and females. A NAA10 p.(Tyr43Ser) variant was identified in two brothers with syndromic intellectual disability (ID) and long QT [22]. Their mildly affected mother was a heterozygous carrier, and $\mathrm{X}$-inactivation studies showed a normal non-skewed (random) inactivation pattern in her blood. Two brothers and an unrelated male with developmental delay (DD), ID and cardiac abnormalities were found to harbor a NAA10 p.(Ile72Thr) variant [23]. Five NAA10 variants, p.(Val107Phe), p.(Phe128Leu), p.(Phe128Ile), p.(Val111Gly), and p.(Arg116Trp) have been reported in unrelated girls with random X-inactivation patterns in lymphocytes and varying degrees of ID [24-26]. Eighteen females with ID and DD have been found to harbor a NAA10 p.(Arg83Cys) variant, which makes it the most commonly reported NAA10 variant to date [25]. Furthermore, a NAA10 p.(Arg83His) variant has been reported in two unrelated boys with ID, DD and hypertrophic cardiomyopathy [27]. A recent comprehensive cohort presented 23 individuals harboring ten different NAA10 variants, whereof seven were previously undescribed [28]. Generally, the overlapping phenotypes for NAA10 patients are ID, DD and cardiac abnormalities. However, distinct phenotypes may also be correlated to specific effects of the different variants [25]. NAA10 polyadenylation signal variants [29], a splice-donor variant [30] and a small (4 bp) deletion in the penultimate exon [28] were found to cause Lenz microphthalmia syndrome (OMIM\#309800) in males, while female carriers of the respective variants were unaffected in the described families.

Thus far, little is known about the exact disease mechanisms causative of disease in NAA10 patients. Here we describe a ten-year-old girl with a novel de novo NAA10 p.(His16Pro) missense variant and severe syndromic ID, severely delayed motor and language development and disturbed behavior with hyperactivity.

\section{Case presentation}

\section{Patient description}

The patient is a girl, now 10 years old, second child of a non-consanguineous couple of Austrian descent (Fig. 1a, b, c). The patient has a healthy older brother; one pregnancy was lost at an early stage. Parental age at delivery was 35 years each. The girl was born at term (39th week of gestation) by vaginal delivery - after manual turning from breech position in the 36th week of gestation. Birth 

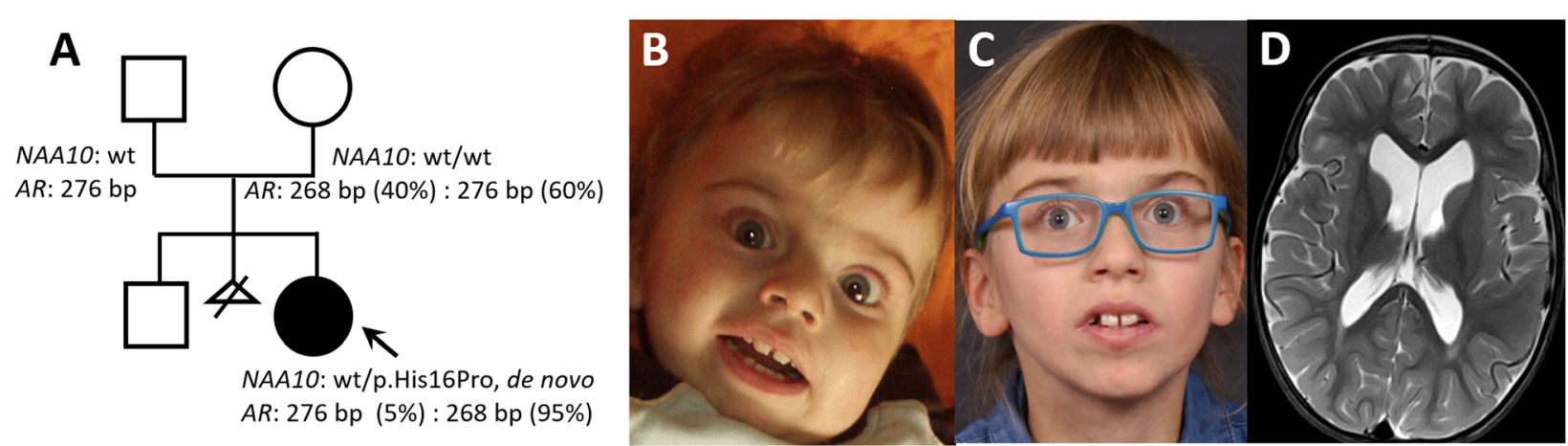

Fig. 1 a Pedigree with NAA10 genotypes, repeat length at the AR-locus and X-inactivation pattern. The NAA10 mutation is absent in blood of the parents; the maternal X-inactivation pattern is random, the patient's pattern is skewed with the paternal allele ( $276 \mathrm{p}$ ) being almost completely digested and the maternal allele ( $268 \mathrm{bp}$ ) almost undigested; $\mathbf{b}$ patient at the age of 1 year and 4 months and $\mathbf{c} 9$ years and 6 months; $\mathbf{d}$ cMRI at the age of 2 years and 2.5 months shows a moderate dilatation of the ventricular system and extracerebral cerebrospinal fluid (CSF) spaces

weight was $3440 \mathrm{~g}$ (75th centile), length was $52 \mathrm{~cm}$ (75th centile) and birth occipital head circumference (OFC) was $34 \mathrm{~cm}$ (25th centile). She had club feet a small atrial septal defect (ASD) which resolved spontaneously later and a hip dysplasia (grade IIC - D). Postnatally, oxygen mask needed to be applied at night because of oxygen desaturations. Because of symptoms resembling interstitial lung disease (chronic tachydyspnea, recurrent pneumonia and bronchitis) a lung biopsy was performed at the age of 3 years without revealing any specific findings.

Breast feeding was initially possible without any problems. However, increasing feeding difficulties required feeding via PEG tube from the age of 7 months until the age of 3 years and 9 months.

At the age of 2 years and 2 months brain imaging (cMRI) showed moderate dilatation of ventricular system and extracerebral CSF spaces (Fig. 1d).

At the age of 3 years myopia ( $-4.75 \mathrm{dpt})$ was noted.

At the age of 4 years she started to walk independently with a wide based gait; her height and OFC were in the lower normal range with $97 \mathrm{~cm}$ (25th centile) and $49 \mathrm{~cm}$ (2nd - 9th centile).

At her latest examination she was 9 years and 11 months of age and showed short stature with a height of $120 \mathrm{~cm}$ (0.4th centile, $-3 \mathrm{SD})$, and an OFC of $49 \mathrm{~cm}$ $(<0.4$ th centile, $-4 \mathrm{SD})$ indicating secondary microcephaly. She is very meagre with little subcutaneous fat. Her upper front teeth are broad and she has discrete facial dysmorphisms (thin horizontal eyebrows, slight hypertelorism, long palpebral fissures, wide mouth, deep nasal root, Fig. 1b, c).

At that age she had normal findings in cardiological investigations including normal ECG without arrhythmias and normal ultrasound investigation.

Skeletal findings include a progressive pectus excavatum, scoliosis, sandal gap and slightly broad end-phalanges of the thumb and first toe. The length of her legs is unequal, which is compensated for by heightened heels.

At the age of 10 years she is non verbal and is not able to understand words. A limited form of communication is possible using gestures. She is not diaper free yet. IQ was not formally tested, but ID can be described as severe.

Her behavior is extremely hyperactive with stereotypic actions, restlessness and a short attention span.

Whole exome sequencing (WES) revealed a novel heterozygous de novo missense-variant in NAA10 (NM 003491.3) c.[47A > C];[=] (p.[His16Pro];[=]).

\section{NAA10 sequence- and structural analysis}

A NAA10 multiple sequence alignment showed that His16 is conserved in H. sapiens, M. musculus, $R$. norvegicus, $D$. rerio, $X$. laevis, but not in $S$. pombe, suggesting that His16 may be important for protein function or stability in higher eukaryotes (Fig. 2a). A structural analysis of NatA revealed that His16 is situated in the $\alpha 1$ helix of NAA10 which is part of the NAA10-NAA15 binding interface (Fig. 2b). The side chain of His16 is facing outside of NAA10 towards NAA15 and the complex-bound ligand $\mathrm{IP}_{6}$. In silico interaction predictions in PyMOL revealed that His 16 potentially interacts with $\mathrm{IP}_{6}$ and Trp486 of NAA15, indicating that His16 may be important for binding of NAA15 as well as $\mathrm{IP}_{6}$. Furthermore, the introduction of proline in position 16 was predicted by DynaMut to increase the flexibility in the $\alpha 1$ helix (Fig. 2c), most likely perturbing the interactions mediated by His16 and maybe also other interactions between NAA10 $\alpha 1$ helix and NAA15. Altogether, the in silico analyses indicate that the NAA10 p.(His16Pro) variant could hamper binding of NAA15 and the ligand $\mathrm{IP}_{6}$, potentially affecting NatA complex formation and catalytic activity. 


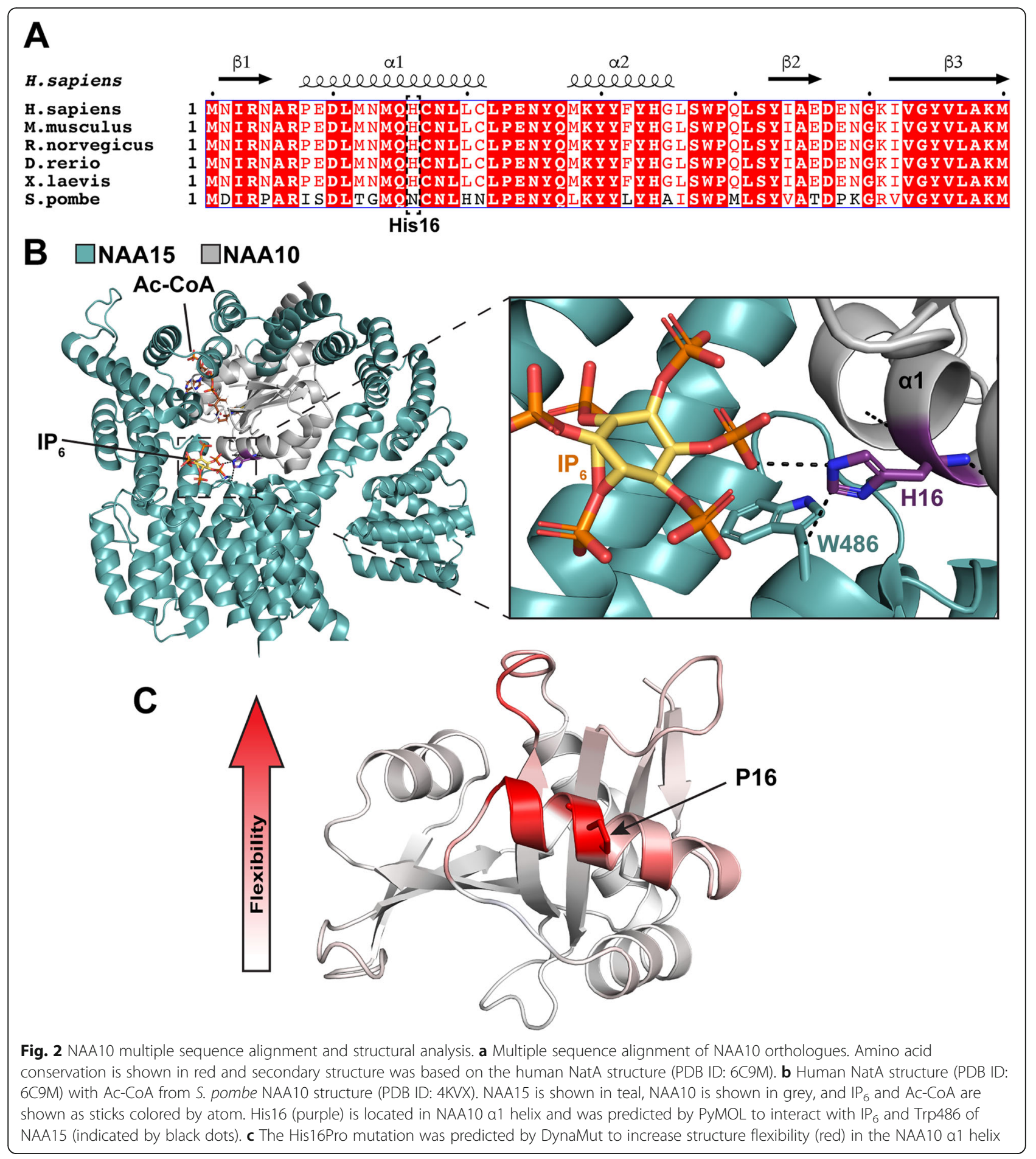

NatA complex formation and catalytic activity

To assess how the NAA10 p.(His16Pro) variant might affect NatA complex formation and the enzyme's catalytic activity in comparison to NAA10 WT, V5-tagged NAA10 was immunoprecipitated from transfected HeLa cells. While NAA10-WT-V5 co-immunoprecipitated endogenous NAA15 as expected, NAA10 H16P-V5 in contrast pulled out less NAA15 (Fig. 3a). This suggests that the NAA10 p.(His16Pro) variant has impaired binding affinity for NAA15. Further, the immunoprecipitates were subjected to Nt-acetylation assays to measure catalytic activity (Fig. 3b). Nt-acetylation assays were performed using the NatA substrate $\mathrm{SESS}_{24}$ and the in vitro monomeric NAA10 substrate $\mathrm{EEEI}_{24}$. The 


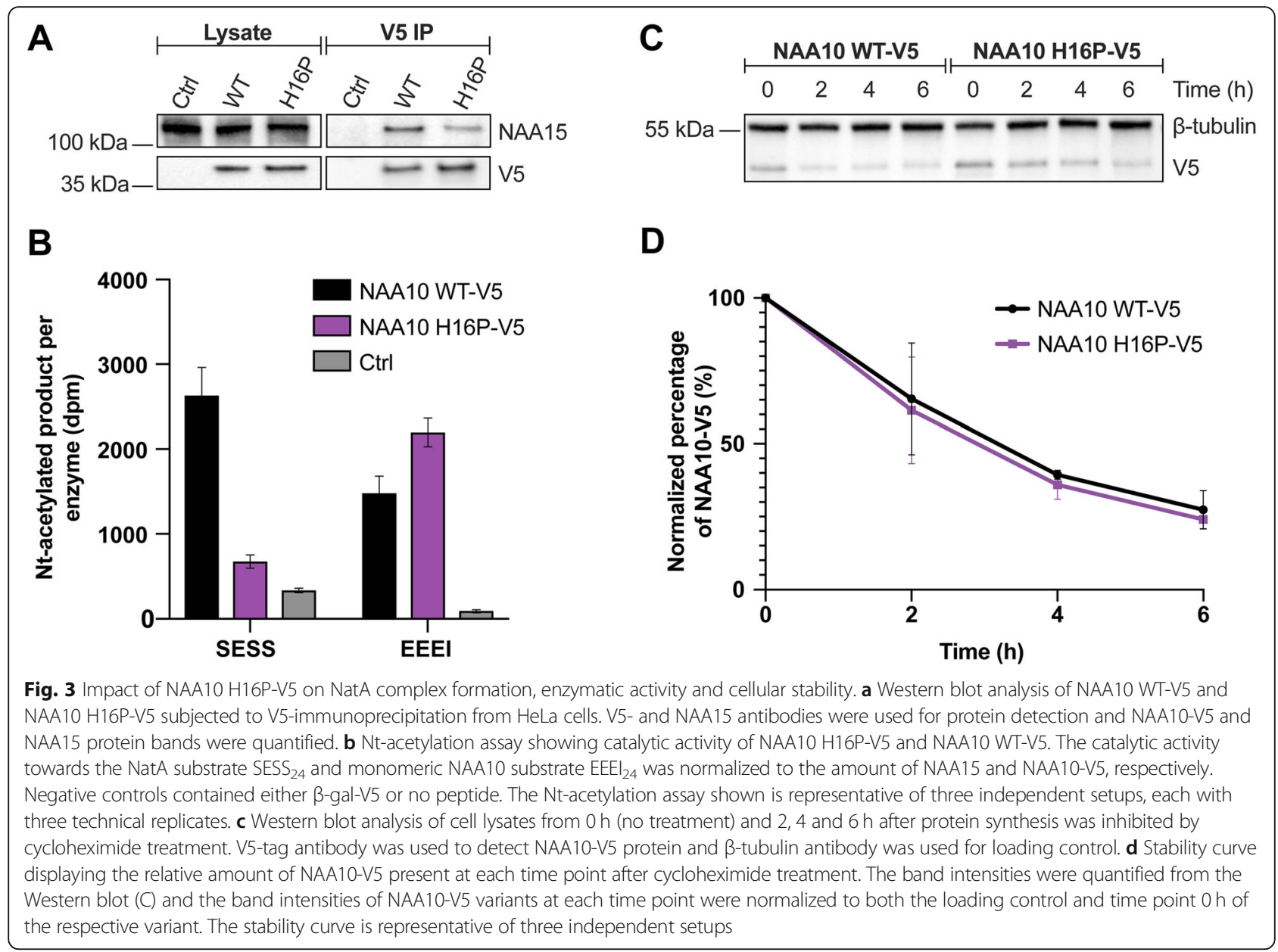

measured catalytic activity towards $\mathrm{SESS}_{24}$ and $\mathrm{EEEI}_{24}$ was normalized to the amount of NAA15 (equals the amount of NatA complex) and NAA10-V5 (both monomeric and complexed state), respectively. As shown in Fig. 3b, NAA10 H16P-V5 displayed an approximately 4fold decrease in NatA catalytic activity towards $\mathrm{SESS}_{24}$ as compared to NAA10 WT-V5. However, the monomeric NAA10 catalytic activity towards $\mathrm{EEEI}_{24}$ was increased 1.5-fold for NAA10 H16P-V5 relative to NAA10 WT-V5. Altogether the activity data indicate that the NAA10 p.(His16Pro) variant has aberrant NatA catalytic activity as well as impaired binding of NAA15, while the monomeric NAA10 catalytic activity appears to be intact.

\section{NAA10 WT-V5 and NAA10 H16P-V5 protein turnover}

The cellular stabilities of NAA10 WT-V5 and NAA10 H16P-V5 were assessed by cycloheximide chase experiments. V5-tagged NAA10 variants were overexpressed in HeLa cells followed by cycloheximide treatment. The protein turnover was determined by Western blot analysis using antibodies against the V5-tag and $\beta$-tubulin as a loading control (Fig. 3c). As seen in Fig. 3d, the protein turnover rate was equal between NAA10 WT-V5 and NAA10 H16P-V5, suggesting that the NAA10 p.(His16Pro) variant does not affect the cellular stability of NAA10.

\section{Whole exome sequencing}

Single whole exome sequencing and filtering of variants was performed as described previously [31]. The de novo status of the NAA10 variant was determined by targeted sanger sequencing of DNA from the parents. Paternity was confirmed by sanger sequencing of X-chromosomal SNPs.

\section{Multiple sequence alignment, structural analysis and databases}

Clustal Omega [32] and ESPript 3.0 [33] was used to create a NAA10 multiple sequence alignment. PyMOL [34] and DynaMut [35] was used to visualize and study the human NatA structure (PDB ID: 6C9M) [36]. The human NatA structure was merged with acetyl-CoA from the $S$. pombe NAA10 structure (PDB ID: 4KVX) [6] in PyMOL. The NAA10 p.(His16Pro) variant was absent in 18,000 samples of the Munich exome server and absent in the ExAC and gnomAD databases. 


\section{$\mathrm{X}$-inactivation test and direction of skewing}

$\mathrm{X}$-inactivation status in DNA from leukocytes was determined according to standard protocols [37]. Length polymorphisms of the repeat in the AR gene were determined in DNA from blood of the father (276 bp), the mother $(268 \mathrm{bp} / 276 \mathrm{bp})$ and the patient $(268 \mathrm{bp} / 276 \mathrm{bp})$.

\section{Site directed mutagenesis}

The NAA10 (NM_003491.3) c.47A > C p.(His16Pro) missense variant was introduced into a pcDNA3.1/ NAA10-V5-His plasmid using Q5 Site Directed Mutagenesis Kit (New England Biolabs) with forward primer 5'-AACATGCAGCCCTGCAACCTC-3' and reverse primer 5' -CATTAGGTCCTCTGGCCT-3'. The annealing temperature was $64^{\circ} \mathrm{C}$. The $N A A 10$ sequence was verified by sequencing.

\section{Transfection and immunoprecipitation}

HeLa (ATCC ${ }^{\oplus} \mathrm{CCL}^{2} 2^{\mathrm{Tm}}$ ) were transfected 2 days prior to immunoprecipitation (IP) using X-tremeGENE 9 DNA Transfection Reagent (Roche). $10 \times 10^{6} \mathrm{HeLa}$ cells transfected with $6 \mu \mathrm{g}$ of pcDNA3.1/NAA10-H16P-V5, $6 \mu \mathrm{g}$ of pcDNA3.1/LacZ-V5 (control-IP) or $4 \mu \mathrm{g}$ of pcDNA3.1/ NAA10-WT-V5 and $2 \mu \mathrm{g}$ of empty pcDNA3.1/V5 were used per IP sample. Harvested cells were lysed for 15 min at $4{ }^{\circ} \mathrm{C}$ in $1 \mathrm{ml} \mathrm{IPH}$ lysis buffer $(50 \mathrm{mM}$ Tris- $\mathrm{HCl}$ $\mathrm{pH} 8.0,150 \mathrm{mM} \mathrm{NaCl}, 5 \mathrm{mM}$ EDTA, 0.5\% NP-40, 1× complete EDTA-free protease inhibitor cocktail (Roche)). Samples were then centrifuged $\left(17000 \times g, 4{ }^{\circ} \mathrm{C}\right)$ for $5 \mathrm{~min}$ to remove cell debris. The supernatants were incubated with $4 \mu \mathrm{g}$ V5-tag antibody (Invitrogen, \#R960-25) on a tube rotator for $2 \mathrm{~h}$ at $4{ }^{\circ} \mathrm{C}$. Each sample was then mixed with $40 \mu \mathrm{l}$ Dynabeads Protein G (Invitrogen). Following overnight incubation, the magnetic beads were washed three rounds in IPH lysis buffer and two rounds in acetylation buffer (50 mM Tris- $\mathrm{HCl} \mathrm{pH} 8.5,1 \mathrm{mM}$ EDTA, 10\% Glycerol). Finally, the IP samples were resuspended in $90 \mu \mathrm{l}$ acetylation buffer and used in a Nt-acetylation assay. The IP samples were also analyzed by Western blot using V5-tag antibody (1:5000, Invitrogen, \#R960-25) and NAA15 antibody (1:2000, BioGenes [3]). ChemiDoc XRS+ system (Bio-Rad) and Imagelab Software (Bio-Rad) were used for imaging and quantification of Western blots.

\section{In vitro Nt-acetylation assay}

The catalytic activity of NAA10 WT-V5 and NAA10 H16P-V5 was tested in Nt-acetylation assays as described [38]. The $25 \mu \mathrm{l}$ reaction mixtures consisted of $10 \mu \mathrm{l} \mathrm{IP}$ sample, $50 \mu \mathrm{M}\left[{ }^{14} \mathrm{C}\right]$-Ac-CoA (Perkin-Elmer), $200 \mu \mathrm{M}$ substrate peptide SESS $_{24}$ (SESSSKSRWGRPVGRRRRPV RVYP) or EEEI $_{24}$ (EEEIAALRWGRPVGRRRRPVRVYP) (BioGenes), and acetylation buffer.

Substrate peptide was substituted with acetylation buffer in negative controls. The reactions were incubated on a thermomixer $\left(37^{\circ} \mathrm{C}, 1400 \mathrm{rpm}\right)$ and stopped after $30 \mathrm{~min}$. Reaction mixtures were transferred to P81 phosphocellulose filter squares (Millipore). Filter squares were washed in $10 \mathrm{mM}$ HEPES buffer ( $\mathrm{pH} 7.4)$, dried and added to tubes with $5 \mathrm{ml}$ Ultima Gold F scintillation cocktail (Perkin-Elmer). $\left[{ }^{14} \mathrm{C}\right]$-acetyl signal was measured using a TriCarb 2900TR Liquid Scintillation Analyzer (Perkin-Elmer). The $\left[{ }^{14} \mathrm{C}\right]$-acetyl signal for the reactions containing $\mathrm{SESS}_{24}$ and $\mathrm{EEEI}_{24}$ were normalized to the amount of NAA15 and NAA10-V5, respectively, after Western blot analysis.

\section{Cycloheximide chase experiment}

NAA10 protein turnover was assessed by cycloheximide chase experiment as previously described [26]. In brief, $3 \times 10^{5} \mathrm{HeLa}$ cells (ATTC, CCL-2) per well were transfected with either $1.8 \mu \mathrm{g}$ pcDNA3.1/NAA10-H16P-V5 or $1.2 \mu \mathrm{g}$ pcDNA3.1/NAA10-WT-V5 and $0.6 \mu \mathrm{g}$ empty pcDNA3.1/V5 using X-tremeGENE 9 DNA Transfection Reagent (Roche). Culture medium was replenished after $4 \mathrm{~h}$ and cells were grown for 2 days. To start the chase experiment, cells were subjected to cycloheximide $(50 \mu \mathrm{g} / \mathrm{ml})$ and then harvested at specific time points $(0$, 2, 4 and $6 \mathrm{~h}$ ). Each time point sample was analyzed by Western blot using V5-tag antibody (1:5000, Invitrogen, \#R960-25) and $\beta$-tubulin antibody (1:3000, Sigma, T5293). The amount of NAA10-V5 present at timepoints 2,4 and $6 \mathrm{~h}$ post treatment was normalized to the amount of NAA10-V5 present at timepoint $0 \mathrm{~h}$ as well as $\beta$-tubulin as a loading control.

\section{Discussion and conclusions}

Here we characterize a previously undescribed novel de novo NAA10 p.(His16Pro) missense variant in a ten-yearold female with severe syndromic intellectual disability, severely delayed motor and language development and hyperactive behavior.

In silico analyses were performed to investigate how the NAA10 p.(His16Pro) variant may affect intra- and intermolecular interactions (Fig. 2). His16 is strongly conserved in higher eukaryotes (Fig. 2a) and the $\alpha 1$ helix in which His16 is located mediates interactions important for binding of NAA15 [6]]. His16 was predicted to form interactions with both Trp486 of NAA15 and $\mathrm{IP}_{6}$ (Fig. 2b). $\mathrm{IP}_{6}$ is a ligand thought to have an evolutionarily conserved stabilizing role in NatA due to its identification in both human and S. cerevisiae NatA crystal structures [36, 39]. The His16Pro mutation introduces a proline with a cyclic side chain which has more conformational rigidity compared to other amino acids. Since the $\mathrm{C} \alpha-\mathrm{N}$ bond of a proline in a peptide is incorporated in the ring-structure, the torsion angles $\phi$ and $\psi$ of proline are not able to adopt a suitable $\alpha$-helix formation. Furthermore, proline will typically introduce a destabilizing kink when located in 
the middle of $\alpha$-helices due to its backbone's inability to make hydrogen bonds. The introduction of proline in position 16 most likely destabilizes the $\alpha 1$ helix of NAA10 which may lead to increased flexibility in the $\alpha 1$ helix $\mathrm{N}$ and C-terminus as well as close neighboring residues (Fig. 2c). Thus, the NAA10 p.(His16Pro) variant may debilitate binding of NAA15 and $\mathrm{IP}_{6}$ due to loss of interactions mediated by His 16 as well as other NAA10 $\alpha 1$-helix residues due to increased local flexibility. Consequently, the NatA complex formation and/or catalytic activity of NAA10 p.(His16Pro) may be impaired.

The functional impact of NAA10 p.(His16Pro) was investigated in a Nt-acetylation assay using immunoprecipitated V5-tagged NAA10 H16P and NAA10 WT (Fig. 3a and b). In agreement with the in silico analyses, less NAA15 was co-immunoprecipitated with the NAA10 H16P-V5 variant as compared to NAA10 WT-V5, indicating that NAA10 p.(His16Pro) has a reduced binding affinity for NAA15. Furthermore, the Nt-acetylation assay revealed a 4-fold reduced catalytic activity of NAA10 H16P-V5 relative to NAA10 WT-V5 towards the NatA substrate $\mathrm{SESS}_{24}$ when normalized to the amount of NAA15 present in the reaction. Contrarily, the catalytic activity of NAA10 H16P-V5 towards the in vitro monomeric NAA10 substrate $\mathrm{EEEI}_{24}$ was increased as compared to NAA10 WT-V5. However, since NAA10 H16P-V5 pulled down less NAA15 compared to NAA10 WT-V5, the NAA10 H16P-V5 sample contained more monomeric NAA10. Monomeric NAA10 has a 1000fold higher activity towards $\mathrm{EEEI}_{24}$ than NatA [9], and thus the actual monomeric NAA10 catalytic activity of NAA10 H16P-V5 and NAA10 WT-V5 is probably close to equal. In sum, these results suggest that the NatA complex formation and NatA catalytic activity of NAA10 p.(His16Pro) is impaired, whereas the monomeric NAA10 NAT activity is intact. The cycloheximide chase experiments revealed that NAA10 H16P-V5 did not have an altered cellular protein turnover compared to NAA10 WT-V5 (Fig. 3c and d) suggesting that the in vivo stability of this protein variant is not compromised.

NAA10 is an X-linked gene, and males hemizygous for pathogenic NAA10 variants have generally been more severely affected compared to heterozygous females. In fact, several previously reported heterozygous females have shown mild to no symptoms due to skewed Xinactivation towards the disease allele [20-22, 24, 30]. The blood leukocyte X-inactivation pattern of the female reported herein was skewed (95/5) towards the maternally inherited X-chromosome. The determination of the parental allele that harbours the NAA10-variant was hampered by the lack of nearby SNPs in this family. Thus at the moment we do not know which is the parental allele the NAA10-variant in our patient is located on. Further experiments are necessary, e.g. using length polymorphisms of nearby microsatellites to address this question.
Despite the increasing number of pathogenic NAA10 variants reported, the underlying disease mechanisms remain elusive. Originally, the phenotype severity was thought to be directly linked to the reduction in catalytic activity [24]. However, this has been shown to be far more complex, and different NAA10 variants are likely to operate through a variation of disease mechanisms affecting different NAA10 functions [22, 25]. In conclusion, our in silico and functional characterization of the NAA10 p.(His16Pro) variant indicate that loss of NatA-mediated $\mathrm{Nt}$-acetylation is causative of disease in the female reported herein. Further studies would be needed to determine whether KAT- or non-catalytic roles of NAA10 are also affected and contributing factors to disease.

\section{Abbreviations}

NAA10: N-alpha acetyltransferase 10; NAA15: N-alpha acetyltransferase 15 . NAT: N-terminal acetyltransferase; NatA: N-terminal acetyltransferase A; ACCoA: Acetyl coenzyme A; ID: Intellectual disability; DD: Developmental delay; WES: Whole exome sequencing; IP: Immunoprecipitation

\section{Acknowledgements}

We are very grateful for the participation of the family involved in this study. The authors would like to thank the Exome Aggregation Consortium (ExAC) and the groups that provided exome variant data for comparison. A full list of contributing groups can be found at http://exac.broadinstitute.org/about

\section{Authors' contributions}

NM and CD performed experiments, analyzed results, and made figures. IB and NM wrote the manuscript. IB and JAM consulted the patients, analyzed WES data, designed and led the study. EB reviewed the CMRI and wrote respective passage in the manuscript. SE performed experiments. TA and RR designed and analyzed experiments, supervised NM and CD, led the study. All authors read, approved and commented on the final manuscript.

\section{Funding}

The work has been supported by the Research Council of Norway (Project 249843), the Norwegian Health Authorities of Western Norway (Project 912176), the Norwegian Cancer Society, the ERA-Net E-Rare project GENOMIT FWF I 2741-B26 and the Vereinigung zur Förderung Pädiatrischer Forschung und Fortbildung Salzburg. The funding bodies had no role in the design of the study, collection, analysis, or interpretation of data or in writing the manuscript.

\section{Availability of data and materials}

All data generated or analyzed during this study are included in this published article and its supplementary information files. Generated plasmids are available from the corresponding author on request. Information on the NAA10 missense variant c.[47A > C]; [=] (p.[His16Pro]; $[=]$ ) has been submitted to to the NCBI-Database ClinVar (ClinVar accession SCV001164597). Sequence analyses were performed using NCBI Reference Sequence database, GenBank: NM_003491.3.

Ethics approval and consent to participate

Not applicable. Written informed consent was obtained from the parents of the patient.

\section{Consent for publication}

Written informed consent to publish identifying images and personal and clinical details was obtained from the parents. A copy of the written consent is available for review by the Editor of this journal.

\section{Competing interests}

The authors declare that they have no competing interests. 


\section{Author details}

'Einheit für Klinische Genetik, Universitätsklinik für Kinder- und Jugendheilkunde, Paracelsus Medizinische Universität, Müllner Hauptstraße 48, A-5020 Salzburg, Austria. ${ }^{2}$ Department of Biomedicine, University of Bergen, Bergen, Norway. ${ }^{3}$ Children's University Hospital, Zürich, Switzerland. ${ }^{4}$ Children's Hospital, Paracelsus Medical University, Salzburg, Austria. ${ }^{5}$ Department of Biological Sciences, University of Bergen, Bergen, Norway. ${ }^{6}$ Department of Surgery, Haukeland University Hospital, Bergen, Norway.

\section{Received: 31 March 2020 Accepted: 12 July 2020}

\section{Published online: 22 July 2020}

\section{References}

1. Aksnes H, Ree R, Arnesen T. Co-translational, post-translational, and noncatalytic roles of N-terminal Acetyltransferases. Mol Cell. 2019;73(6):1097-114.

2. Arnesen T, Van Damme P, Polevoda B, Helsens K, Evjenth R, Colaert N, Varhaug JE, Vandekerckhove J, Lillehaug JR, Sherman F, et al. Proteomics analyses reveal the evolutionary conservation and divergence of $\mathrm{N}$-terminal acetyltransferases from yeast and humans. Proc Natl Acad Sci U S A. 2009; 106(20):8157-62.

3. Arnesen T, Anderson D, Baldersheim C, Lanotte M, Varhaug JE, Lillehaug JR. Identification and characterization of the human ARD1-NATH protein acetyltransferase complex. Biochem J. 2005;386(Pt 3):433-43.

4. Arnesen T, Anderson D, Torsvik J, Halseth HB, Varhaug JE, Lillehaug JR. Cloning and characterization of hNAT5/hSAN: an evolutionarily conserved component of the NatA protein N-a-acetyltransferase complex. Gene. 2006; 371(2):291-5.

5. Arnesen T, Starheim KK, Van Damme P, Evjenth R, Dinh H, Betts MJ Ryningen A, Vandekerckhove J, Gevaert K, Anderson D. The chaperone-like protein HYPK acts together with NatA in Cotranslational N-terminal acetylation and prevention of Huntingtin aggregation. Mol Cell Biol. 2010; 30(8):1898-909.

6. Liszczak G, Goldberg JM, Foyn H, Petersson EJ, Arnesen T, Marmorstein R. Molecular basis for $\mathrm{N}$-terminal acetylation by the heterodimeric NatA complex. Nat Struct Mol Biol. 2013;20(9):1098-105.

7. Gautschi M, Just S, Mun A, Ross S, Rucknagel P, Dubaquie Y, EhrenhoferMurray A, Rospert $\mathrm{S}$. The yeast $\mathrm{N}$ (alpha)-Acetyltransferase NatA is quantitatively anchored to the ribosome and interacts with nascent polypeptides. Mol Cell Biol. 2003;23(20):7403-14

8. Magin RS, Deng S, Zhang H, Cooperman B, Marmorstein R. Probing the interaction between NatA and the ribosome for co-translational protein acetylation. PLoS One. 2017;12(10):e0186278.

9. Van Damme P, Evjenth R, Foyn H, Demeyer K, De Bock P-J, Lillehaug $J$ R, Vandekerckhove J, Arnesen T, Gevaert K. Proteome-derived peptide libraries allow detailed analysis of the substrate specificities of $\mathrm{N}$ (alpha)-acetyltransferases and point to hNaa10p as the posttranslational actin N (alpha)-acetyltransferase. Mol Cell Proteomics. 2011:10(5):M110.004580

10. Seo JH, Park J-H, Lee EJ, Vo TTL, Choi H, Kim JY, Jang JK, Wee H-J, Lee HS, Jang SH, et al. ARD1-mediated Hsp70 acetylation balances stress-induced protein refolding and degradation. Nat Commun. 2016;7:12882.

11. Lim J-H, Park J-W, Chun Y-S. Human arrest defective 1 acetylates and activates beta-catenin, promoting lung cancer cell proliferation. Cancer Res. 2006:66(22):10677-82.

12. Lim J-H, Chun Y-S, Park J-W. Hypoxia-inducible factor-1a obstructs a Wnt signaling pathway by inhibiting the hARD1-mediated activation of $\beta$ catenin. Cancer Res. 2008;68(13):5177-84.

13. Lee C-C, Peng S-H, Shen L, Lee C-F, Du T-H, Kang M-L, Xu G-L, Upadhyay AK, Cheng X, Yan Y-T, et al. The Role of N-a-acetyltransferase 10 Protein in DNA Methylation and Genomic Imprinting. Mol Cell. 2017; 68(1):89-103.e107.

14. Lee C-F, Ou DS, Lee S-B, Chang L-H, Lin R-K, Li Y-S, Upadhyay AK, Cheng X, Wang Y-C, Hsu H-S, et al. HNaa10p contributes to tumorigenesis by facilitating DNMT1-mediated tumor suppressor gene silencing. J Clin Invest. 2010;120(8):2920-30

15. Lee M-N, Kweon HY, Oh GT. N-a-acetyltransferase 10 (NAA10) in development: the role of NAA10. Exp Mol Med. 2018:50(7):87.

16. Ree R, Myklebust LM, Thiel P, Foyn H, Fladmark KE, Arnesen T. The Nterminal acetyltransferase Naa10 is essential for zebrafish development. Biosci Rep. 2015;35(5):e00249.
17. Ingram AK, Cross GAM, Horn D. Genetic manipulation indicates that ARD1 is an essential Na-acetyltransferase in Trypanosoma brucei. Mol Biochem Parasitol. 2000;111(2):309-17.

18. Wang Y, Mijares M, Gall MD, Turan T, Javier A, Bornemann DJ, Manage K, Warrior R. Drosophila variable nurse cells encodes arrest defective 1 (ARD1), the catalytic subunit of the major N-terminal acetyltransferase complex. Dev Dyn. 2010;239(11):2813-27.

19. Wu Y, Lyon GJ. NAA10-related syndrome. Exp Mol Med. 2018;50(7):85.

20. Rope Alan F, Wang K, Evjenth R, Xing J, Johnston Jennifer J, Swensen Jeffrey J, Johnson WE, Moore B, Huff Chad D, Bird Lynne M, et al. Using VAAST to identify an X-linked disorder resulting in lethality in male infants due to N-terminal Acetyltransferase deficiency. Am J Hum Genet. 2011:89(1):28-43.

21. Myklebust LM, Van Damme P, Støve SI, Dörfel MJ, Abboud A, Kalvik TV, Grauffel C, Jonckheere V, Wu Y, Swensen J, et al. Biochemical and cellular analysis of Ogden syndrome reveals downstream Nt-acetylation defects. Hum Mol Genet. 2015:24(7):1956-76.

22. Casey JP, Støve SI, McGorrian C, Galvin J, Blenski M, Dunne A, Ennis S, Brett F, King MD, Arnesen T, et al. NAA10 mutation causing a novel intellectual disability syndrome with long QT due to N-terminal acetyltransferase impairment. Sci Rep. 2015:5:16022.

23. Støve SI, Blenski M, Stray-Pedersen A, Wierenga KJ, Jhangiani SN, Akdemir ZC, Crawford D, McTiernan N, Myklebust LM, Purcarin G, et al. A novel NAA10 variant with impaired acetyltransferase activity causes developmental delay, intellectual disability, and hypertrophic cardiomyopathy. Eur J Hum Genet. 2018;26(9):1294-305.

24. Popp B, Støve SI, Endele S, Myklebust LM, Hoyer J, Sticht H, Azzarello-Burri S, Rauch A, Arnesen T, Reis A. De novo missense mutations in the NAA10 gene cause severe non-syndromic developmental delay in males and females. Eur J Hum Genet. 2015:23(5):602-9.

25. Saunier C, Støve SI, Popp B, Gérard B, Blenski M, Ahmew N, Bie C, Goldenberg P, Isidor B, Keren B, et al. Expanding the phenotype associated with NAA10-related N-terminal acetylation deficiency. Hum Mutat. 2016; 37(8):755-64.

26. McTiernan N, Støve SI, Aukrust I, Mårli MT, Myklebust LM, Houge G, Arnesen T. NAA10 dysfunction with normal NatA-complex activity in a girl with nonsyndromic ID and a de novo NAA10 p.(V111G) variant - a case report. BMC Med Genet. 2018;19(1):47.

27. Ree R, Geithus AS, Tørring PM, Sørensen KP, Damkjær M, Lynch SA, Arnesen T, study DDD. A novel NAA10 p.(R83H) variant with impaired acetyltransferase activity identified in two boys with ID and microcephaly. BMC Med Genet. 2019;20(1):101.

28. Cheng H, Gottlieb L, Marchi E, Kleyner R, Bhardwaj P, Rope AF, Rosenheck S, Moutton S, Philippe C, Eyaid W, et al. Phenotypic and biochemical analysis of an international cohort of individuals with variants in NAA10 and NAA15. Hum Mol Genet. 2019;28(17):2900-19.

29. Johnston JJ, Williamson KA, Chou CM, Sapp JC, Ansari M, Chapman HM Cooper DN, Dabir T, Dudley JN, Holt RJ, et al. NAA10 polyadenylation signal variants cause syndromic microphthalmia. J Med Genet. 2019; 56(7):444-52.

30. Esmailpour T, Riazifar H, Liu L, Donkervoort S, Huang VH, Madaan S, Shoucri BM, Busch A, Wu J, Towbin A, et al. A splice donor mutation in results in the dysregulation of the retinoic acid signalling pathway and causes Lenz microphthalmia syndrome. J Med Genet. 2014;51(3):185-96.

31. Kremer LS, Bader DM, Mertes C, Kopajtich R, Pichler G, luso A, Haack TB, Graf E, Schwarzmayr T, Terrile C, et al. Genetic diagnosis of Mendelian disorders via RNA sequencing. Nat Commun. 2017;8:15824.

32. Sievers F, Wilm A, Dineen D, Gibson TJ, Karplus K, Li W, Lopez R, McWilliam $H$, Remmert M, Söding J, et al. Fast, scalable generation of high-quality protein multiple sequence alignments using Clustal omega. Mol Syst Biol. 2011;7(1):539.

33. Robert X, Gouet P. Deciphering key features in protein structures with the new ENDscript server. Nucleic Acids Res. 2014;42(W1):W320-4.

34. Schrödinger LLC. The PyMOL Molecular Graphics System, Version 2.3: 2019.

35. Rodrigues $\mathrm{CH}$, Pires DE, Ascher DB. DynaMut: predicting the impact of mutations on protein conformation, flexibility and stability. Nucleic Acids Res. 2018;46(W1):W350-5.

36. Gottlieb L, Marmorstein R. Structure of Human NatA and Its Regulation by the Huntingtin Interacting Protein HYPK. Structure. 2018;26(7):925-935.e928.

37. Allen RC, Zoghbi HY, Moseley AB, Rosenblatt HM, Belmont JW. Methylation of Hpall and Hhal sites near the polymorphic CAG repeat in the human 
androgen-receptor gene correlates with X chromosome inactivation. Am J Hum Genet. 1992;51(6):1229-39.

38. Drazic A, Arnesen T. [14C]-Acetyl-Coenzyme A-Based In Vitro N-Terminal Acetylation Assay. In: Schilling O, editor. Protein Terminal Profiling: Methods and Protocols. New York: Springer New York; 2017. p. 1-8.

39. Deng S, Magin RS, Wei X, Pan B, Petersson EJ, Marmorstein R. Structure and Mechanism of Acetylation by the N-Terminal Dual Enzyme NatA/Naa50 Complex. Structure. 2019;27(7):1057-1070.e1054.

\section{Publisher's Note}

Springer Nature remains neutral with regard to jurisdictional claims in published maps and institutional affiliations.

Ready to submit your research? Choose BMC and benefit from:

- fast, convenient online submission

- thorough peer review by experienced researchers in your field

- rapid publication on acceptance

- support for research data, including large and complex data types

- gold Open Access which fosters wider collaboration and increased citations

- maximum visibility for your research: over $100 \mathrm{M}$ website views per year

At $\mathrm{BMC}$, research is always in progress.

Learn more biomedcentral.com/submissions 